\title{
Evolution Characteristics of the Information Literacy Education Policy for Chinese College Students
}

\author{
Wei Liu', Chunyan Liu' ${ }^{2 *}$ \\ ${ }^{1}$ College of Management Science, Chengdu University of Technology, Chengdu 610059, Sichuan Province, China \\ ${ }^{2}$ College of Foreign Languages and Cultures, Chengdu University of Technology, Chengdu 610059, Sichuan Province, China \\ *Corresponding author: Chunyan Liu, cheyanne2819886258@163.com
}

\begin{abstract}
In order to cultivate information literacy among college students, the Chinese government has formulated a series of relevant policies as well as revised and adjusted the policy priorities along with the times. Guided by co-word and social network analysis, this study analyzes 170 policy texts that have been promulgated by the Chinese government from 1981 to 2020. Based on the clustering results of high-frequency keywords, this study explores the characteristics of policy evolution and its influencing factors from three dimensions: policy themes, contents of information literacy education, and the methods for cultivating information literacy education. Several suggestions have also been put forward in this article to improve the information literacy education policy for Chinese college students.
\end{abstract}

Keywords: Information literacy education; Policy evolution; Social network analysis; Co-word analysis

Publication date: September 2021; Online publication: September 30, 2021

\section{Introduction}

With the development of information technology, the demand for talents with high information literacy is gradually increasing. College students shoulder an essential mission in the socialist construction, which is to develop new thinking in learning, cultivate innovation skills, and improve in information literacy. There are many research on information literacy education for college students; in addition, policy trend literatures and research are abundant as well ${ }^{[1]}$. The Chinese government has promulgated a series of standardized regulations, policies, and rules. In January 1981, the Ministry of Education (MOE) promulgated the Regulations of the People's Republic of China on the Work of Libraries in Higher Education Institutions as China's first official document emphasizing on university libraries. It is the mark whereby university libraries in China have begun to enter into a stage with laws to comply with ${ }^{[2]}$. In February 2002, MOE issued the General Provisions of the General Higher Education Library Regulations (Revised). It clearly states that the main tasks of university libraries are to carry out information literacy education, cultivate information awareness among college students, and acquire literature information ${ }^{[3]}$. In 2012, MOE promulgated the Ten-Year Development Plan for Education Informatization (2010-2020), which clearly states that it is necessary to promote informatization, strengthen the deep integration of higher education and information technology, as well as establish high-quality educational resources for sharing ${ }^{[4]}$. In 2018, according to the Action Plan for Education Informatization 2.0, MOE emphasized on establishing a scientific, suitable, and highly operable evaluation index system as well as an evaluation model for students' information literacy ${ }^{[5]}$. This policy marks the strategic deepening stage of information literacy education 
for college students in China.

Although the information literacy education policy is deepening, there are only a few research on it. At present, the research mainly focuses on literature; thus, unable to depict or describe the overall evolution characteristics of information literacy education. Based on the clustering results of high-frequency words, this article constructs a comprehensive analysis framework of the information literacy education policy for college students in China from three dimensions: policy themes, contents of information literacy education, and the methods for cultivating information literacy education. The qualitative and quantitative analysis, objective and transparent description of various stages of information literacy education policy among college students, as well as the exploration of policy goals ${ }^{[6]}$ can clarify the scope of policy evolution and grasp the direction of its development.

\section{Data source and research method}

\subsection{Data source}

The information literacy education policy for college students issued by the Central Government of China from 1981 to 2020 was used as the research subject. The data used in this study were selected from the websites of Chinese government departments, such as the MOE. In order to search for and collect relevant policy texts, this study used this method: "Title" = (higher institution OR university OR university library) AND (information literacy). Finally, 150 influential policy texts were selected, and a policy text database was established (Figure 1).

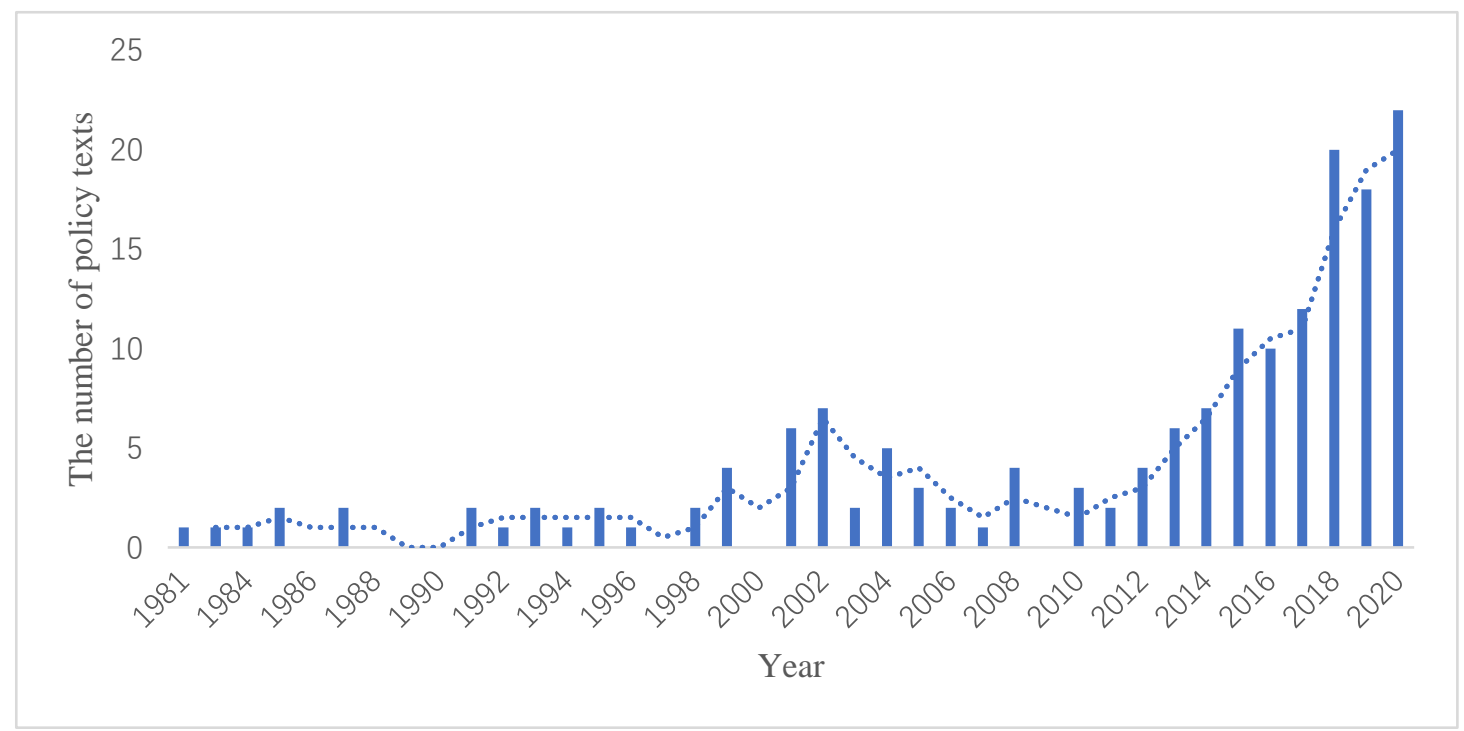

Figure 1. The distribution of information literacy education policy for college students in China from 1981 to 2020

\subsection{Research method}

The academic literature keywords were used as the research subject in the co-word analysis, which is an important research method in bibliometrics. In the past, when the government was developing policy literature, it is common to regard keywords that represent the core content of a document as the theme words ${ }^{[7]}$. Applying the social network analysis to policy text analysis, high-frequency keywords extracted from enterprises and government agencies related to a specific policy area can be analyzed by comparing the similarity of individual connection structures ${ }^{[8]}$. Therefore, the terms used in this study include terms from early literature and bibliometrics. The co-word and social network analysis were used in this study to obtain representative policy terms and explore their evolutionary characteristics. 


\section{Data analysis}

\subsection{From the initial exploration stage to the steady development stage (1981-2011)}

This study used ROST CM6 to create a co-word matrix. UCINET was then used to turn the co-word matrix into a network diagram to perform cluster analysis ${ }^{[9]}$. This provides a clear logic map between hot research issues and high-frequency keywords in information literacy education policy for college students at this stage (Figure 2).
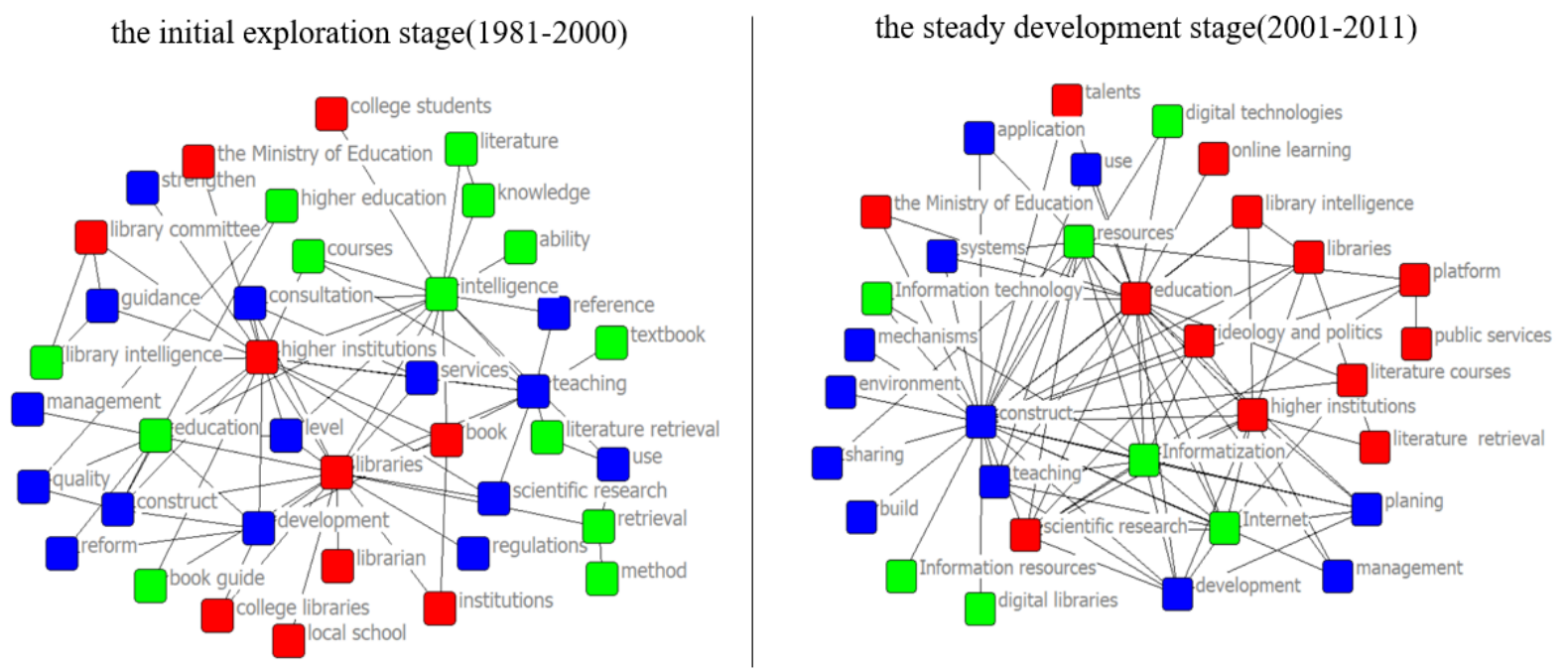

Figure 2. The distribution of high-frequency keywords of information literacy education policy for Chinese college students from 1981 to 2011

From Figure 2, several deductions can be derived.

(1) In regard to the policy themes, China has not yet developed a clear concept of "information literacy education" and an independent policy system at the initial stage. Information literacy education is mainly carried out by literature retrieval. The development of information literacy education is primarily on the policy documents related to "higher education," "library," as well as "teaching," and is carried out toward informatization.

(2) In regard to the contents of information literacy education, the terms "literature courses," "literature retrieval," "library intelligence," as well as "ideology and politics," are relatively centralized. At this stage, information literacy education is mainly about retrieving literature to improve students' ability to use it, teaching them the knowledge and methods of literature, as well as carrying out ideological and political education to enhance the overall capacity of college students.

(3) In terms of the methods for cultivating information literacy education, it is mainly through teaching to improve the information quality of college students and serve as a bridge between higher education institutions and libraries. The high-frequency words indicated that cultivation includes the offline training of literature retrieval courses, extending to the online digital library. Therefore, the cultivation of online query and retrieval is not limited by the access to information resources but indirectly promotes the information retrieval skills of college students.

\subsection{From the flourishing stage to the strategic deepening stage (2012-2020)}

These policy documents indicate that the growth of information literacy education for Chinese college students has gone through preparation and theoretical advocacy as well as has rapidly launched into a 
critical development stage of information-based education. The high-frequency keywords at these stages were compiled into a co-word matrix. ROST CM6 was used to form a network graph of the co-word matrix to perform the corresponding cluster analysis (Figure 3) ${ }^{[9]}$.
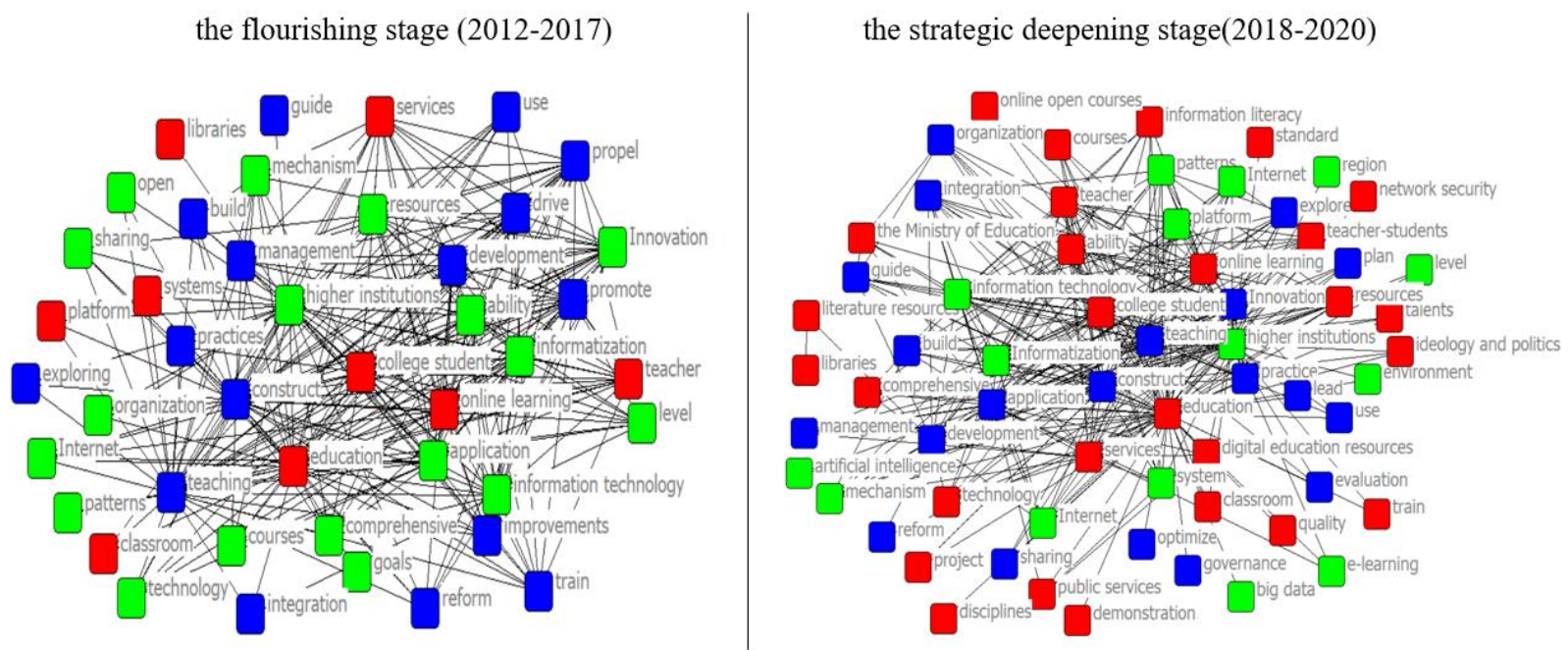

Figure 3. The distribution of high-frequency keywords of information literacy education policy for Chinese college students from 2012 to 2020

According to Figure 3, several deductions can be derived.

(1) In regard to policy themes, "teaching," "informatization," and other related keywords appeared more frequently at these stages, indicating that information literacy education still relies on information technology. With the growth of the internet, various virtual technologies and software are used for teaching, thus making the course more vivid and easy for students to understand ${ }^{[10]}$. At the same time, there is an increased in keywords such as "innovation," "technology," and "ability" in the strategic deepening stage, indicating that information literacy has started to focus on teaching and curriculum innovation. Cultivating college students' information literacy is gradually changing from traditional literature retrieval to integrating information technology and education.

(2) In regard to the contents of information literacy education, the improvement of college students' information literacy skills lies in the deep integration of information technology and education as well as the full use of the internet, communication satellite, etc., to promote information literacy education toward digitalization, networking, and modernization. The growth of information technology has transformed the traditional teaching model and improved the practical ability of information retrieval among college students. Higher education institutions have adopted ideological and political education as well as internet thinking to promote the close integration of ideological and political work with information awareness.

(3) In regard to the methods of cultivating information literacy education, the theme words appeared more frequently at these two stages. It shows that the Chinese government is gradually building a robust platform of "Internet Plus Education." Further promoting the deep integration of information technology and education, such as big data and AI, can encourage teaching and management transformation. At the same time, there is a significant increase in the theme words, indicating that the main subjects of information literacy improvement are college students and teachers. 


\section{Conclusion}

By analyzing the characteristics of different stages, this article draws several conclusions.

(1) In terms of policy, the information literacy policy system for Chinese college students has four stages: exploration, steady development, vigorous growth (flourishing), and strategic deepening. In the exploration stage, the concept of "information literacy" had not been formed in China, nor the independent policy system. At this time, the cultivation of information literacy was mainly realized by literature retrieval courses. During its steady development, the government focused on the construction of university libraries, public services, and other infrastructure. In addition to that, the information literacy education shifted its focus from literature retrieval skills to information consciousness and morality. In the flourishing stage, digital and online education promoted the deep integration of information technology and education. In the strategic deepening stage, the Chinese government encouraged teaching, curriculum innovation, and information literacy education, in addition to the emergence of big data, artificial intelligence, and diversified teaching.

(2) In terms of policy evolution, the theme gradually changed from a single to compound type, from the construction of college information infrastructure to the deep integration of technology into education, as well as from the deep promotion of information literacy education to the promotion of network literacy culture. The contents of information literacy education are improving as exemplified by the shift from traditional literature retrieval to information consciousness and morality. The cultivation of information literacy has undergone a gradual transformation from literature retrieval courses, campus network construction, information literacy education, and the combination of online and multimedia teaching to curriculum innovation. In regard to policy measures, its evolvement began from the construction of university libraries to the introduction of diversified information resources, the reform of the information literacy curriculum, and the improvement of college students' information literacy evaluation system.

\section{Disclosure statement}

The authors declare that there is no conflict of interest.

\section{References}

[1] Xiao X, 2021, On the Theoretical Origin, Connotation and Components of Information Literacy - Also on International Experience of Information Literacy Education. e-Education Research, 42(08): 116121, 128 [In Chinese].

[2] Department of Science and Education, National Sports Commission, 1993, Selected Documents of Current Higher Education 1980-1992, Beijing Institute of Physical Education Press, Beijing, 572 [In Chinese].

[3] The Ministry of Education, 2002, Notice of the Regulations for Libraries of General Institutions of Higher Education (Revised). Ministry of Education Political Daily, (04): 156-160 [In Chinese].

[4] The Central Committee of the Communist Party of China (CPC), 2010, The State Council Issued the National Medium and Long-Term Education Reform and Development Plan (2010-2020). People's Education, (17): 2-15 [In Chinese].

[5] Sha H, Li M, 2020, A Review of Research on College Students' Information Literacy Education from the Perspective of Educational Informationization 2.0. Jiangsu Higher Vocational Education, 20(01): 105-109, 115 [In Chinese]. 
[6] Zhang C, Guan J, 2020, Research on the Evolution of a Policy System by the Content Analysis on Policy Texts: Evidence from the Innovation and Entrepreneurial Policy System in China. Management Review, 32(05): 138-150 [In Chinese].

[7] Zheng S, Peng R, Gao C, 2019, The Logic of Change and Prospect of Environmental Policy of China: Based on Co-word and Cluster Analysis. Journal of Jishou University (Social Sciences), 40(02): 7-20 [In Chinese].

[8] Cheng RM, 2017, An Analysis of Information Literacy Co-authorship Networks in China Based on the Social Network Analysis Method. Library Science Research \& Work, (09): 51-56 [In Chinese].

[9] Zhao G, Liu J, Wu Y, et al., 2019, Research on Co-word Network of Guangdong Science and Technology Financial Policy Based on Grounded Theory and Text Mining. Science and Technology Management Research, 39(03): 51-57 [In Chinese].

[10] $\mathrm{Hu} \mathrm{A}$, 2018, The Research of Online Information Literacy Education of Hainan Based on Constructivism Learning Theory. Journal of Academic Library and Information Science, 36(03): 115 119 [In Chinese]. 